\title{
Toxin-Induced Models of Parkinson's Disease
}

\author{
Jordi Bové, Delphine Prou, Céline Perier, and Serge Przedborski \\ Departments of Neurology and Pathology, and the Center for Neurobiology and Behavior, Columbia University, New York, \\ New York 10032
}

\begin{abstract}
Summary: Parkinson's disease (PD) is a common neurodegenerative disease that appears essentially as a sporadic condition. It results mainly from the death of dopaminergic neurons in the substantia nigra. PD etiology remains mysterious, whereas its pathogenesis begins to be understood as a multifactorial cascade of deleterious factors. Most insights into PD pathogenesis come from investigations performed in experimental models of $\mathrm{PD}$, especially those produced by neurotoxins. Although a host of natural and synthetic molecules do exert deleterious effects on dopaminergic neurons, only a handful are used in living laboratory animals to recapitulate some of the hall-
\end{abstract}

marks of PD. In this review, we discuss what we believe are the four most popular parkinsonian neurotoxins, namely 6-hydroxydopamine (6-OHDA), 1-methyl-4-phenyl-1,2,3,6tetrahydropyridine (MPTP), rotenone, and paraquat. The main goal is to provide an updated summary of the main characteristics of each of these four neurotoxins. However, we also try to provide the reader with an idea about the various strengths and the weaknesses of these neurotoxic models. Key Words: Parkinson's disease, experimental models, neurodegeneration, pathogenesis, 6-hydroxydopamine, MPTP, rotenone, paraquat.

\section{INTRODUCTION}

Parkinson's disease (PD) is currently regarded as the most common degenerative disorder of the aging brain after the Alzheimer's dementia. Most epidemiological studies estimate that over one million individuals in the United States are carrying the diagnosis of PD and that roughly 50,000 new cases arise each year. ${ }^{1}$ Clinically, PD is characterized by the tetrad of tremor at rest, slowness of voluntary movements, rigidity, and postural instability. ${ }^{1}$ The cardinal biochemical abnormality in PD is the profound deficit in brain dopamine level, primarily, but not exclusively, attributed to the loss of neurons of the nigrostriatal dopaminergic pathway. ${ }^{2}$ This pathway is made of dopaminergic neurons whose cell bodies are located in the substantia nigra pars compacta and whose axons and nerve terminals project to the striatum. ${ }^{2}$ However, the neuropathology of PD is far from being restricted to the nigrostriatal pathway, and histological abnormalities are also found in many other dopaminergic and nondopaminergic cell groups. ${ }^{2}$ Aside from the loss of neurons, other prominent neuropathological features

Address correspondence and reprint requests to Dr. Serge Przedborski, Departments of Neurology and Pathology, and the Center for Neurobiology and Behavior, Columbia University, 650 West 168th Street, BB-318, New York, NY 10032. E-mail: sp30@ columbia.edu. of PD include gliosis ${ }^{3}$ and the presence of intraneuronal proteinaceous inclusions called Lewy bodies (LBs) in the few remaining substantia nigra dopaminergic neurons. ${ }^{2}$

Until now, very little is known about why and how the PD neurodegenerative process begins and progresses. Yet over the last two decades, tremendous strides toward acquiring a better knowledge of both the etiology and pathogenesis of PD have been achieved, thanks to numerous elegant clinical studies and investigations performed in autopsy materials and in vitro and in vivo experimental models of PD. ${ }^{2}$ Despite these unquestionable advances, we still have major gaps in our understanding of the molecular and cellular biology of PD. Consequently, investigators still rely heavily on experimental models of PD to obtain greater insights into its cause, but more particularly into its pathogenesis. Whereas recent genetic discoveries have lead to a number of different genetic models of PD, none of these shows the typical degeneration of dopaminergic neurons. Thus far, among the various accepted experimental models of PD, neurotoxins have remained the most popular tools to produce selective neuronal death in both in vitro and in vivo systems.

In this paper, we will review the key neurotoxic models of PD, namely those produced by the toxins 6-hydroxydopamine (6-OHDA), 1-methyl-4-phenyl-1,2,3,6tetrahydropyridine (MPTP), rotenone, and paraquat. 
Other less often used neurotoxins such as isoquinoline derivatives and methamphetamine will not be discussed here, but information regarding those toxins can be found (see Ref. 4). Finally, two points must be emphatically stressed at the outset of this review paper. First, in vitro data will only be mentioned whenever necessary as this paper will focus on in vivo studies. This should not be taken as evidence undermining the significance of in vitro studies, but merely as a deliberate choice made by these authors. Second, some parts of this review represent shortened and updated pieces from previous reviews written by these authors. Should the reader be interested in these other reviews, see Refs. 2 and 4-6.

\section{6-OHDA, OR THE PROTOTYPIC OXIDATIVE STRESS NEUROTOXIN}

On an historical note, it must be remembered that among all the selected techniques developed to study specific structures of the nervous system, the noradrenergic analog 6-OHDA and several other synthesized analogs have been introduced as catecholaminergic neurotoxins over 30 years ago. ${ }^{7}$ Ever since, these neurotoxin compounds, especially 6-OHDA, have remained extensively used for both in vitro and in vivo investigations. Because of practical considerations, in living animals 6-OHDA has been used essentially in small animals such as rodents. In some instances, however, it has also been administered in nonhuman primates ${ }^{8-11}$ and, in particular for studies geared toward investigating the cardiovascular system, in dogs. ${ }^{12-14}$

6-OHDA shares some structural similarities with dopamine and norepinephrine, exhibiting a high affinity for several catecholaminergic plasma membrane transporters such as the dopamine (DAT) and norepinephrine transporters (NET). Consequently, 6-OHDA can enter both dopaminergic and noradrenergic neurons and inflict damage to the catecholaminergic pathways of both the peripheral and the central nervous systems. Therefore, should the goal be the production of a model of PD, with a specific lesion of the nigrostriatal dopaminergic pathway, it is imperative that attention be paid to the mode of administration of 6-OHDA (see below) as well as to several important technical details which have been reviewed by Jonsson. ${ }^{7,15}$

With respect to its mode of action, it is well accepted that 6-OHDA destroys catecholaminergic structures by a combined effect of reactive oxygen species (ROS) and quinones. ${ }^{16}$ This view stems primarily from the demonstration that 6-OHDA, once dissolved in an aerobic and alkaline milieu, readily oxidizes, yielding hydrogen peroxide $\left(\mathrm{H}_{2} \mathrm{O}_{2}\right)$ and para-quinone $\mathrm{e}^{17,18}$ as depicted in Figure 1. Although the chemical reaction that underlies 6-OHDA-induced neurotoxicity appears straightforward, it is in fact a remarkably complicated reaction that does

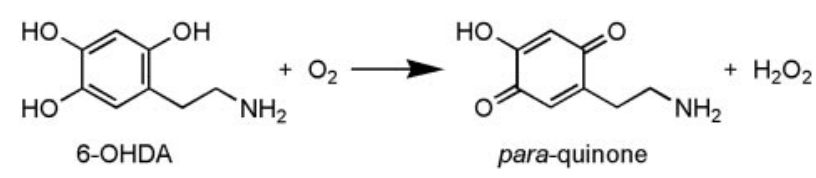

FIG. 1. Oxidation of 6-OHDA. Used with permission from Przedborski and Ischiropoulos. Reactive oxygen and nitrogen species: weapons of neuronal destruction in models of Parkinson's disease. Antioxid Redox Signal 7:685-693. Copyright (c) 2005, Mary Ann Liebert, Inc. All rights reserved. ${ }^{6}$

not occur as a spontaneous oxidation by molecular oxygen. This chemical reaction has been reviewed elsewhere and will thus not be discussed herein, but any reader interested in acquiring further information regarding this aspect of 6-OHDA biology is encouraged to refer to Przedborski and Ischiropoulos. ${ }^{6}$

Like other parkinsonian neurotoxins to be discussed here, 6-OHDA can be administrated by systemic injection. However, contrary to MPTP, rotenone, or paraquat, this route of administration will not produce the desired nigrostriatal lesion. Instead, this is the preferred route of 6-OHDA administration to cause a chemical sympathectomy by damaging the peripheral nervous system. ${ }^{7}$ Indeed, 6-OHDA poorly crosses the blood-brain barrier (BBB), hence failing to accumulate within the brain parenchyma to meaningful neurotoxic concentrations following systemic injections. To circumvent this problem, 6-OHDA has to be injected directly into the brain either free-hand or by stereotaxic means. As such, over the years several local sites of injection have been used to damage the central dopaminergic pathways including intraventricular, intracisternal, and intracerebral. ${ }^{7} \mathrm{Al}-$ though these models of lesioning have been primarily utilized in rats, sometimes mice and even monkeys have also been subjected to 6-OHDA lesioning. ${ }^{9-11,19-22}$

As far as the intraventricular and intracisternal administration of 6-OHDA is concerned, both produce a bilateral catecholaminergic lesion, observed within a few hours of the injection of the toxin, with generally very limited re-growth of affected nerve fibers. ${ }^{7}$ However, when a bilateral 6-OHDA lesion is severe, animals often die primarily due to the occurrence of marked aphagia, adipsia, and seizures. ${ }^{23,24}$ Accordingly, a much more popular and practical model of 6-OHDA is the unilateral intracerebral injection. The latter can be successfully used to target a particular catecholaminergic pathway of the brain. ${ }^{25,26}$ To specifically damage the nigrostriatal dopaminergic pathway, 6-OHDA is injected stereotaxically into the substantia nigra, the medial forebrain bundle (that comprises the nigrostriatal tract), or the striatum. ${ }^{7,27}$ After 6-OHDA injections into substantia nigra or the medial forebrain bundle, dopaminergic neurons start to die within the first $24 \mathrm{~h}$ and show a nonapoptotic morphology. ${ }^{28}$ Maximal reduction of striatal dopamine level is reached within 3-4 d after lesion, ${ }^{29}$ and, in most studies, residual striatal dopamine content is less than 
$20 \%$ of controls. Interestingly, despite the dramatic loss of dopaminergic neurons in the substantia nigra after a medial forebrain bundle injection of a high dose of 6-OHDA, levels of extracellular dopamine are still close to normal. ${ }^{30}$ Perhaps this can be explained by a somatodendritic release of dopamine from the few spared neurons in the substantia nigra. When injected into the striatum, 6-OHDA produces a more protracted retrograde degeneration of the nigrostriatal system which can last from 1-3 wk after lesion, ${ }^{31,32}$ and the dying neurons exhibit a varied morphology including some features reminiscent of apoptosis. ${ }^{33}$ In addition to the lesion of the dopaminergic system, gliosis is also a prominent feature of the 6-OHDA model.${ }^{34}$ Many data support the idea that the glial response in experimental models of $\mathrm{PD}$, especially of microglia, exacerbates the degeneration of dopaminergic neurons. ${ }^{3}$ However, other studies also indicate that, under specific circumstances, the activation of astrocytes, produced in rats by the administration of interleukine-1 $\beta$ before a 6-OHDA-induced lesion, mitigates rather than enhances toxicity on dopaminergic neurons. ${ }^{35}$ If confirmed, this observation would argue that the temporal relationship between the initiation of glial activation and dopaminergic neuronal death is critical in defining the role of the different kinds of glial cells in the neurodegenerative process. Finally, LB formation has never been convincingly demonstrated in the brain of 6-OHDA-lesioned rats, a lack that will be regarded by some as a major shortcoming of this model.

In terms of behavioral abnormalities, Rodriguez and collaborators ${ }^{36}$ have reported that the few rats that survive and recover normal ingestion and weight following bilateral 6-OHDA lesion exhibit motor abnormalities that are partially corrected by drugs that stimulate dopaminergic receptors. Further description of the motor abnormalities of rats with bilateral 6-OHDA lesion can be found in Cenci and co-authors. ${ }^{37}$ In contrast, unilateral injections cause a typical asymmetric circling motor behavior whose magnitude in rodents depends on the degree of nigrostriatal lesion. ${ }^{31,38,39}$ This specific behavioral abnormality is most prominent after administration of drugs that stimulate dopaminergic receptors, such as apomorphine (rotation away from the lesion), or drugs that stimulate the release of dopamine, such as amphetamine (rotation toward the lesion), due to physiologic imbalance between the lesioned and the unlesioned striatum. Quantification of this turning behavior has been used extensively to assess the antiparkinsonian potency of new drugs, ${ }^{40}$ transplantation, and gene therapies ${ }^{41,42}$ and to study the motor fluctuations in the chronic treatment with levodopa. ${ }^{43,44}$ Moreover, Olsson et al. ${ }^{45}$ developed a very useful stepping test for unilateral-lesioned-rats that shows a forelimb akinesia that is improved by dopaminergic stimulation and which is reminiscent of the slowness of movements seen in PD patients. Several additional motor tests have also been developed and validated in 6-OHDA rats, including a model of L-DOPA-induced dyskinesia; all of these are discussed and evaluated in details by Cenci and coauthors elsewhere. ${ }^{37}$

The 6-OHDA model has also been used successfully to demonstrate the importance of dopamine stimulation for the proliferation of precursor cells in both the subependymal and the subgranular zones of the adult brain in rats. ${ }^{46}$ It also allowed to demonstrate that, contrary to earlier reports, there is no evidence for de novo generated dopaminergic neurons in the adult rat substantia nigra. ${ }^{47}$ In conclusion, although technically this specific model may be more challenging to use than some others discussed below, the huge body of work based on its utilization represents a significant impetus for using it in a variety of investigations. In keeping with this, the reader must remember that the unilateral 6-OHDA rat model has been and continues to be one of the most popular experimental models of PD when it comes to the preclinical testing of new symptomatic therapies, neuroprotective strategies (e.g., trophic factor delivery), and transplantation approaches..$^{20,44,48-55}$ Also important to remember is the instrumental role played by the unilateral 6-OHDA rat model in the identification of key neurotransmitter pathways governing the functional neuroanatomy of the basal ganglia. ${ }^{56-60}$ Yet, for studying the fine molecular basis of dopaminergic neuronal death, the stereotaxic injection of 6-OHDA, especially in the substantia nigra, may be problematic as the insult, and the molecular mechanisms of cytotoxicity recruited by it may differ among cells depending if they are located near or far from the site of injection. However, despite this caveat, many data show that 6-OHDA neurotoxicity provokes molecular alterations comparable to those seen in $\mathrm{PD},{ }^{61}$ thus supporting the meaningfulness of this model to explore the mechanisms of neurodegeneration in PD.

\section{THE HUMAN PARKINSONIAN NEUROTOXIN, 1-METHYL-4-PHENYL-1,2,3,6- TETRAHYDROPYRIDINE}

In the early 1980s, several drug users from Northern California developed an acute state of akinesia (initially confused with catatonia) following the intravenous injection of a street preparation of 1-methyl-4-phenyl-4-propionpiperidine (MPPP), an analog of the narcotic meperidine. ${ }^{62}$ After fine detective work, it was found that MPTP, which was inadvertently produced during the illicit synthesis of MPPP, was the culprit behind this dramatic clinical picture. ${ }^{62}$ The chemical structures of MPPP and MPTP are shown in Figure 2.

Since this discovery, the mitochondrial electron transport chain complex I inhibitor MPTP has been used in a 


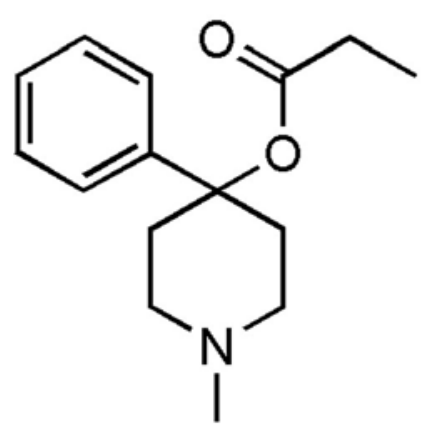

MPPP

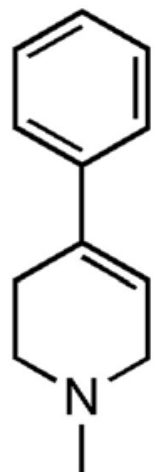

MPTP
FIG. 2. Comparison of chemical structures of MPPP and MPTP.

variety of mammalian species to model PD ranging from nonhuman primates to invertebrates such as worms. ${ }^{63,64}$ During the past years, several reviews dedicated to the MPTP model have been published, of which most focused on the effects of MPTP in small vertebrate animals such as mice. ${ }^{65,66}$ It is to note that dopaminergic neurons in rats are relatively resistant to MPTP-induced neurotoxicity for reasons remaining unclear. As the reader will see in these previous reviews, an enormous body of work regarding the elucidation of the mechanisms of dopaminergic neuron death and the development of experimental neuroprotective therapies has been achieved thanks to the use of the MPTP mouse model of PD. In that sense, a large variety of MPTP administration procedures have been developed; for more details, interested readers can refer to Przedborski et al. ${ }^{65}$ Yet, rarely and often briefly is the question of MPTP in humans and monkeys discussed in these papers. Thus, this review will rather summarize this aspect of the MPTP story, which after all represents a striking competitive advantage over any other model of PD that either lacks or seldom utilizes primates.

It is now well established that MPTP produces, in both humans and monkeys, an irreversible and severe parkinsonian syndrome, characterized by all of the cardinal features of PD, including tremor, rigidity, slowness of movement, postural instability, and even freezing. Yet, in nonhuman primates, the typical $4-\mathrm{Hz}$ resting tremor of PD has only been demonstrated convincingly in the African green monkey ${ }^{67}$; other species of monkeys rather exhibit a postural/action tremor. Cognitive impairments evidenced by poor performances on constructive, verbal fluency and executive function tests were demonstrated in MPTP patients. ${ }^{68,69}$ Apparently, not in humans ${ }^{68,69}$ but in monkeys intoxicated with MPTP, ${ }^{70}$ deficits in maintenance of a response set and difficulties in shifting attentional sets were also found. Impaired ability to sustain spatial attention or to focus attention, deficit in motor readiness and planning, and impaired time estimation were observed in these animals. ${ }^{70}$ Collectively, these cognitive alterations are consistent with attention and executive functional deficits following MPTP intoxication, which is very similar to some of the cognitive alterations seen in PD patients. As emphasized by Stern, ${ }^{68}$ it is also remarkable to note that none of the symptomatic individuals who were intoxicated with MPTP showed neurological signs others than those expected for PD; a similar statement may be true for MPTP-injected monkeys.

On a therapeutic point of view, both humans and monkeys intoxicated with MPTP respond very well to anti-PD treatments such as L-DOPA/carbidopa. However, as in PD patients, ${ }^{71}$ long-term treatment with L-DOPA leads to hyperkinetic motor complications called dyskinesia, which can be as disabling as the parkinsonian symptoms themselves. For instance, among the seven indexed MPTP human cases, five developed dyskinesia within the first year of treatment with L-DOPA/carbidopa ${ }^{72}$ As of yet, the occurrence of L-DOPA-induced motor complications remains a major impediment to the proper management of PD patients. Here, the MPTP monkey model has emerged as an invaluable tool to investigate the molecular basis of these drug-induced abnormal movements and to test therapeutic strategies to control them. ${ }^{73}$ This fact is elegantly illustrated in the recent study by Bézard and collaborators ${ }^{74}$ in which the administration of a D3-dopamine partial agonist was shown to markedly improve L-DOPA-induced dyskinesia in MPTP monkeys, without exacerbating the parkinsonian symptoms.

Neuropathological data in both humans and monkeys ${ }^{75,76}$ indicate that MPTP causes damage to the nigrostriatal dopaminergic pathway identical to that seen in PD. ${ }^{77}$ Moreover, like PD, MPTP causes a greater loss of dopaminergic neurons in the substantia nigra than in the ventral tegmental area ${ }^{78,79}$ and, in monkeys intoxicated with low doses of MPTP (but not in humans), a greater degeneration of dopaminergic nerve terminals in the putamen than in the caudate nucleus. ${ }^{80,81}$ However, as for 6-OHDA, LBs have thus far not been convincingly observed in MPTP-induced parkinsonism ${ }^{76}$; however, in older MPTP-injected monkeys, intraneuronal proteinaceous inclusions reminiscent of LBs have been described ${ }^{82}$ At this point, it is still unknown whether the lack of definite LB formation in the MPTP model is due to the actual molecular mechanism by which MPTP kills dopaminergic neurons or rather the rate by which this neurotoxin destroys dopaminergic neurons. Indeed, all regimens of MPTP intoxication, even if achieved through several low dose injections, provoke in reality a unique or recurrent acute insult.

One other unsettled issue surrounding the neurotoxicity of MPTP is whether an acute exposure to this parkinsonian neurotoxin causes a progressive neurodegen- 
eration. On the one hand, Burns and collaborators ${ }^{83}$ reported the case of a young chemist who developed parkinsonism after substantial laboratory exposure to MPTP and who failed to show any evidence of worsening of his neurological condition over several years. On the other hand, positron emission tomography performed twice, 7 years apart, on 10 individuals exposed to MPTP, revealed worsening of striatal $\left[{ }^{18} \mathrm{~F}\right]$ fluorodopa uptake in these patients. ${ }^{84}$ Moreover, postmortem studies in three individuals who survived 3-16 years after exposure to MPTP $^{85}$ and in six monkeys who survived 5-14 years after exposure to MPTP ${ }^{86}$ showed evidence of extracellular neuromelanin accumulation and activated microglia in the substantia nigra, two neuropathological features consistent with an ongoing degenerative process. As previously speculated ${ }^{66}$ these findings suggest that a single acute MPTP insult can set in motion a self-sustained cascade of cellular and molecular events with long-lasting deleterious effects.

Although a large body of work with MPTP has been accomplished in monkeys, nonhuman primates have not generally been used to study the molecular mechanisms of dopaminergic neurodegeneration; instead, the MPTP administration to mice (essentially by systemic injections), and to a lesser extend to rats (essentially by intracerebral injection) are typically used for such studies. ${ }^{2,66}$ Conversely, the monkey MPTP model remains the gold standard for the assessment of novel strategies and agents for the treatment of PD symptoms. For example, electrophysiological studies in MPTP monkeys have led to the demonstration that hyperactivity of the subthalamic nucleus is a key factor in the development of bradykinesia and rigidity. ${ }^{87}$ This finding prompted investigators to consider targeting the subthalamic nucleus by using high-frequency electric stimulation in an attempt to ameliorate the motor function of PD patients with intractable symptoms. ${ }^{88}$ MPTP-injected monkeys ${ }^{89,90}$ were also used to demonstrate that the delivery of glial-derived neurotrophic factor (GDNF) can limit nigrostriatal dopaminergic neurodegeneration and promote behavioral recovery when given before lesioning animals, ${ }^{90}$ both of which are important advances in the treatment and understanding of PD over the last decade.

\section{ROTENONE: FROM PESTICIDE TO MODELING PD}

Among the toxic animal models of PD, rotenone represents one of the most recently used approaches. ${ }^{91}$ Rotenone is the most potent member of the rotenoids, a family of natural cytotoxic compounds extracted from various parts of Leguminosa plants. Rotenone's chemical structure is presented in Figure 3.

Rotenone is widely used around the world as insecticide and piscicide. ${ }^{92}$ In the United States, treated areas

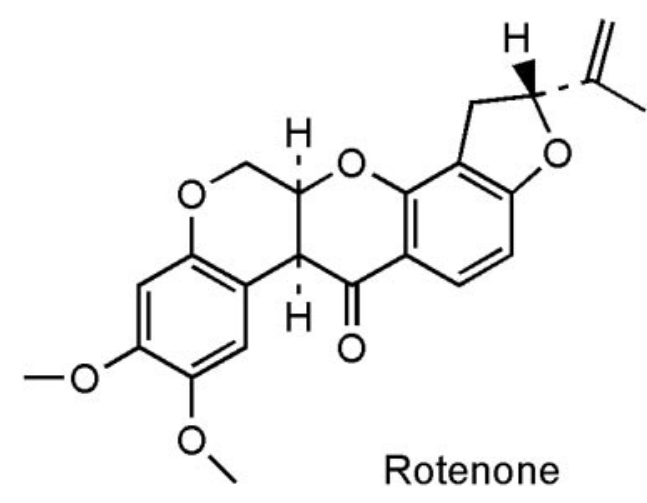

FIG. 3. Chemical structure of rotenone.

are restricted, and treatment dates are selected outside the periods of crop irrigation and swimming. ${ }^{92}$ Rotenone readily breaks down by exposure to sunlight. Nearly all of the toxicity of the compound is lost in 5-6 days of spring sunlight or 2-3 days of summer sunlight. Rotenone is also rapidly broken down in soil and in water. The half-life in both of these environments is between 1 and 3 days. ${ }^{92}$ Because of its short half-life and because it does not readily leach from soil, it is not expected to be a groundwater pollutant. Consequently, the likelihood of PD being caused by an environmental exposure to rotenone is low, to not say null. Conversely, it must be remembered that many environmental neurotoxins other than rotenone have a long half-life. Thus, if rotenone appears an unlikely culprit, several others could account for the epidemiological data showing that the risk of PD increases with exposure to pesticides. ${ }^{93,94}$ The most common way that rotenone exposure to humans would take place is through ingestion. However, absorption in the stomach and intestines is slow and incomplete, and the liver breaks down the compound effectively. These facts make it unlikely that meaningful amounts of rotenone could enter the general circulation, unless enormous quantities are ingested. Consistent with this view is the fact that chronic ingestion of rotenone to rats for 24 months at doses 30 times greater that used to model PD by systemic infusion ${ }^{91}$ failed to cause any behavioral or neuropathological features of the disease. ${ }^{95}$ Nevertheless, there is one case of fatal rotenone poisoning after its acute ingestion. ${ }^{96}$ At autopsy, rotenone was found in the blood, liver, and kidney, but not in brain.

Like MPTP, rotenone is highly lipophilic and thus readily gains access to all organs including the brain. After a single intravenous injection, rotenone reaches maximal concentration in the CNS within 15 min and decays to about half of this level in less than 2 h. ${ }^{97}$ Its brain distribution is heterogeneous, ${ }^{97}$ paralleling regional differences in oxidative metabolism. ${ }^{97}$ Rotenone also freely crosses all cellular membranes and can accumulate in subcellular organelles such as mitochondria. In mitochondria, rotenone impairs oxidative phosphorylation by 
inhibiting reduced nicotinamide adenine dinucleotide (NADH)-ubiquinone reductase activity through its binding to the PSST subunit of the multipolypeptide enzyme complex I of the electron transport chain. ${ }^{98}$ Aside from its action on mitochondrial respiration, rotenone also inhibits the formation of microtubules from tubulin. ${ }^{99,100}$ This effect may be quite relevant to the mechanism of dopaminergic neurodegeneration because excess of tubulin monomers may be toxic to cells. ${ }^{101,102}$ Interestingly, a protein implicated in some familial forms of PD, parkin, appears to bind to tubulin, thereby enhancing the ubiquitination and degradation of misfolded tubulins, an effect that is lacking with the PD-linked parkin mutants. ${ }^{103}$

Rotenone has been used extensively as a prototypic mitochondrial poison in cell cultures, but less frequently in living animals. Exposure of embryonic ventral midbrain cultures to rotenone causes major neurotoxicity, ${ }^{104}$ especially in the presence of microglial cells. ${ }^{105}$ In these two studies, markers of dopaminergic neurons were more altered than those of $\gamma$-aminobutyric acid (GABA) neurons, suggesting greater susceptibility of dopaminergic neurons to such an insult. In animals, rotenone has been administered by different routes. As stated above, oral delivery of rotenone appears to cause little neurotoxicity in animals. ${ }^{95}$ Systemic administration, on the other hand, often causes toxicity and lethality, the degree of which is related to the dose used. Stereotaxic injection of rotenone into the median forebrain bundle depletes striatal dopamine and serotonin. ${ }^{106}$ Rats treated for a week with $10-18 \mathrm{mg} / \mathrm{kg} \cdot$ day of rotenone by intravenous infusion show bilateral lesions of the striatum and the globus pallidus, characterized by neuronal loss and gliosis. ${ }^{107} \mathrm{In}$ that study, the nigrostriatal dopaminergic pathway remained unaffected. ${ }^{107}$ Similarly, subcutaneous injection of either $15 \mathrm{mg} / \mathrm{kg}$ of rotenone once or $1.5 \mathrm{mg} / \mathrm{kg}$ multiple times, although causing fatality, failed to affect striatal dopaminergic contents in mice. ${ }^{108}$ Conversely, Greenamyre and collaborators ${ }^{91,109}$ have found that intravenous and subcutaneous infusion of $2-3 \mathrm{mg} / \mathrm{kg}$. day of rotenone for about 3 weeks to rats does produce nigrostriatal dopaminergic neurodegeneration. By quantitative analysis, it appears that substantia nigra dopaminergic neuron numbers are reduced by about $30 \%$ in rotenone-infused rats compared with vehicle controls. ${ }^{110}$ This study also shows that the numbers of mesolimbic dopaminergic neurons, the cell bodies of which reside adjacent to the substantia nigra in the ventral tegmental area (VTA), are unchanged by rotenone administration. ${ }^{110}$ In the striatum, the average loss of dopaminergic fibers is estimated to be $55 \%$ after rotenone infusion in rats, ${ }^{110}$ that, like in $\mathrm{PD}$, is greater than the loss of substantia nigra dopaminergic neurons. Despite the use of the exact same regimen of rotenone, the severity of the striatal dopaminergic damage in rats within a given ex- periment appears highly variable, ranging from none to near complete..$^{91,109-112}$ After the infusion of rotenone, the loss of tyrosine hydroxylase-positive fibers in the striatum is either focal, showing a zone of maximal loss at the center, or diffuse ${ }^{91,109-112}$; whether the latter represents a more severe lesion of the striatal dopaminergic fiber network than the former remains to be demonstrated. Of note, the focal loss in the center of the striatum seen in some of the lesioned rats is a pattern that differs from that of PD in which the dorsolateral quadrant of the striatum is typically the most affected.

In contrast to the 6-OHDA and MPTP models, in rotenone-infused rats, some of the remaining substantia nigra dopaminergic neurons contain proteinaceous inclusions. ${ }^{91,109,110}$ Like LBs in PD, these inclusions are immunoreactive for both ubiquitin and $\alpha$-synuclein, ${ }^{91}$ and by electron microscopy they appear composed of a dense core with fibrillar peripheral elements. ${ }^{91}$ Likewise in PD in which neurodegeneration extends beyond the dopaminergic system,${ }^{77}$ rotenone infusion is associated with $35 \%$ reduction in serotonin transporter density in the striatum, $26 \%$ reduction of noradrenergic neurons in the locus coeruleus, and 29\% reduction in cholinergic neurons in the pedunculopontine nucleus. ${ }^{110}$

Although the initial descriptive studies did not report any striatal lesion, ${ }^{91}$ the number of dopamine-regulated phosphoprotein-32 projecting neurons, cholinergic interneurons and reduced nicotinamide adenine dinucleotide phosphate (NADPH) diaphorase-positive neurons in the striatum were all found significantly reduced by the infusion of rotenone in rats. ${ }^{110,111}$ Unexpectedly, even at doses of rotenone that did not damage the nigrostriatal dopaminergic pathway in rats, Höglinger and collaborators ${ }^{110}$ still found significant loss of intrinsic striatal neurons. Remarkably, Zhu and collaborators ${ }^{112}$ found that the rotenone-induced intrinsic striatal neuronal loss occurs especially in those rats exhibiting the central striatal loss of tyrosine hydroxylase immunoreactivity mentioned above. These results indicate that rotenone exerts a much more widespread neurotoxicity than initially thought and, contrary to the initial contention, it does not consistently spare striatal postsynaptic dopaminergic neurons. Nor do the nigrostriatal dopaminergic neurons appear preferentially sensitive to rotenone intoxication.

Behaviorally, rotenone-infused rats exhibit reduced mobility, flexed posture, and in some cases rigidity ${ }^{109}$ and even catalepsy. ${ }^{113}$ Four weeks after the infusion of rotenone, rats show more than $70 \%$ reduction in spontaneous motor activity. ${ }^{110}$ Although this required independent confirmation, these motor abnormalities appear to be reversed by L-DOPA administration. ${ }^{114}$ However, some rotenone-infused rats without nigrostriatal dopaminergic lesion have been reported to exhibit a similar set of motor abnormalities. ${ }^{109}$ In addition, indices of dopaminergic damage across different doses of rotenone did 


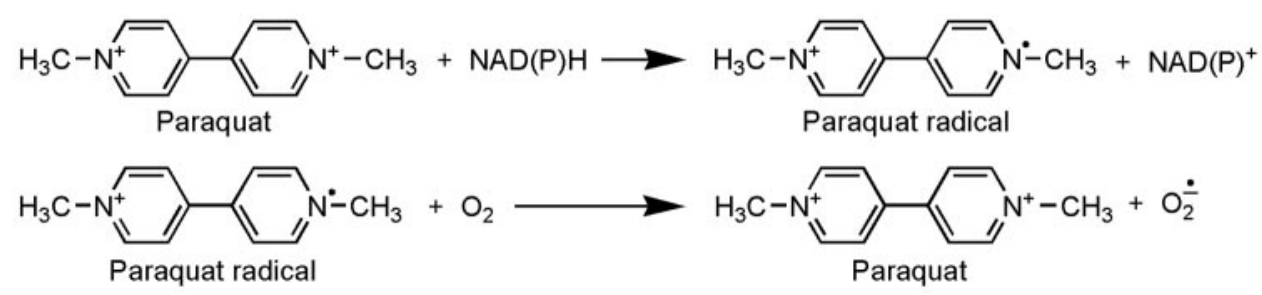

FIG. 4. Reduction-oxidation cycling reaction of paraquat.

not correlate with motor behavior in individual rats. ${ }^{115}$ Therefore, whereas the rotenone-related motor abnormalities are dramatic, it is still questionable that they result from a loss of nigrostriatal dopaminergic neurons and thus the use of these behavioral alterations as an experimental correlate of PD symptoms must be done with caution.

Based on this review, it may be concluded that the chronic administration of rotenone has still a long way to go to become a routine PD model, due to its inconsistent and unpredictable effect on the nigrostriatal pathway. Unless these problems are resolved, it is unlikely that preclinical neuroprotection studies could be carried out successfully in such a model.

\section{THE NEUROTOXIC HERBICIDE PARAQUAT}

The potent herbicide paraquat ( $N, N^{\prime}$-dimethyl-4-4'bipiridinium) is another prototypic toxin known to exert deleterious effects through oxidative stress. Indeed, as reviewed elsewhere, ${ }^{6}$ paraquat toxicity is mediated by redox cycling with cellular diaphorase such as nitric oxide synthase, ${ }^{116}$ yielding ROS. As detailed, ${ }^{6}$ the actual reduction-oxidation cycling reaction of paraquat can thus be depicted in Figure 4. Thus far, there have been several cases of lethal poisoning resulting from ingestion or dermal exposure. ${ }^{117}$ For many years, experimental studies using paraquat were focusing on its effects on lung, liver, and kidney probably because the toxicity induced by this herbicide in these organs is responsible for death after acute exposure. However, significant damage to the brain is seen in individuals who died from paraquat intoxication $^{118,119}$ despite the fact that paraquat poorly crosses the BBB spontaneously. ${ }^{120}$ Furthermore, epidemiological studies have suggested an increased risk for PD due to paraquat exposure, ${ }^{121}$ raising the possibility that paraquat could be an environmental parkinsonian toxin. In keeping with this, it is relevant to point out that paraquat exhibits a striking structural similarity to MPTP toxic metabolite 1-methyl-4-pheylpyridinium $\left(\mathrm{MPP}^{+}\right)$(FIG. 5).

Upon its systemic injection to mice, confusing results have been reported. Some investigators have published reduced motor activity and dose-dependent losses of striatal dopaminergic nerve fibers and substantia nigra neuronal cell bodies in paraquat-treated mice. ${ }^{122}$ It seems quite clear that, in this case, paraquat did enter the brain via the assistance of L-neutral amino acid transports, as pretreatment of animals with L-valine or L-phenylalanine completely prevented neurodegeneration. ${ }^{123}$ Other investigators, however, have initially failed to see any behavioral abnormality or nigrostriatal dopaminergic pathway damage in similarly treated mice, ${ }^{124,125}$ but then ${ }^{125}$ they also found selective nigral dopaminergic cell loss in mice injected with paraquat. ${ }^{126}$ Aside from this bewildering aspect, it must be stressed that levels of $\alpha$-synuclein were reported as elevated in both the frontal cortex and ventral midbrain as well as $\alpha$-synuclein-positive inclusions in substantia nigra neurons of mice treated with paraquat. ${ }^{127}$ As far as the observed $\alpha$-synuclein upregulation is concerned, it may not be a noxious mediator of paraquat-induced neurotoxicity because dopaminergic neurons from transgenic mice expressing high levels of either wild-type or mutant $\alpha$-synuclein appear more resistant to paraquat than those from their nontransgenic counterparts. ${ }^{128}$ Still, we cannot rule out that compensatory mechanisms may have occurred in these constitutive transgenic animals, hence confounding the interpretation of the role that high levels of $\alpha$-synuclein may have on dopaminergic neurons. This cautionary note is particularly relevant in light of the fact that increased expression of $\alpha$-synuclein is noxious in its own right to dopaminergic neurons in humans. ${ }^{129}$ The association of dopaminergic neuron death with $\alpha$-synuclein up-regulation and aggregation suggests that the paraquat model could be quite valuable for reproduc-
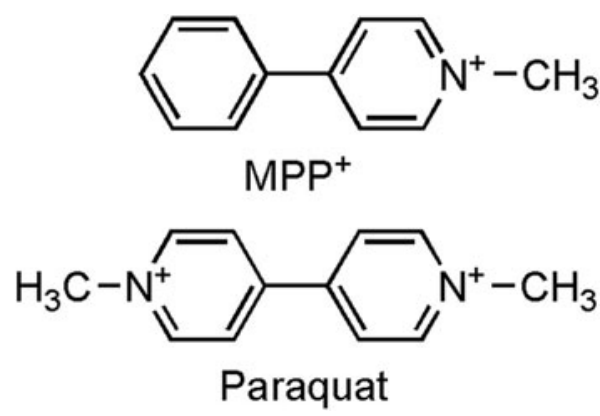

FIG. 5. Comparison of chemical structures of $\mathrm{MPP}^{+}$and paraquat. Used with permission from Przedborski and Ischiropoulos. Reactive oxygen and nitrogen species: weapons of neuronal destruction in models of Parkinson's disease. Antioxid Redox Signal 7:685-693. Copyright @ 2005, Mary Ann Liebert, Inc. All rights reserved. ${ }^{6}$ 
ing a PD-like pathology (e.g., nigral cell loss and synuclein pathology). Although ROS are incontestably involved in the deleterious mechanism by which paraquat kills dopaminergic neurons, the molecular link between oxidative stress and cell death in this model remains unknown. It appears, however, that paraquat can trigger the sequential activation of c-Jun N-terminal kinase (JNK), c-Jun, and caspase-3 both in vitro and in vivo, ${ }^{130}$ suggesting that JNK signaling pathways could mediate paraquat-induced neurodegeneration.

It is worth mentioning that the fungicide manganese ethylenebisdithiocarbamate, or Maneb, which is used in overlapping geographical areas with paraquat, has been shown to decrease locomotor activity and potentiate paraquat effects on the nigrostriatal pathway in mice. ${ }^{124,125}$ In these studies, combined paraquat and Maneb exposures produce greater effects on the dopaminergic system than either of the chemicals alone. ${ }^{124,125}$ However, in none of these studies did the authors assess phenotypic markers for neuronal populations other than the dopaminergic neurons. Thus, whether GABAergic neurons, cholinergic neurons, or even astrocytes are also affected after paraquat injection, which is likely, is unknown. Therefore, at this point it remains unclear whether the observed paraquat/Maneb cytotoxicity is really specific to the dopaminergic systems and could thus be regarded as a reliable experimental model of PD. Interestingly, Maneb has also been used in several studies to ascertain whether a pre- or postnatal insult by an environmental toxicant to the developing brain could give rise to an adult-onset neurodegenerative process involving the nigrostriatal dopaminergic pathway. ${ }^{131,132}$

\section{CONCLUSION}

This review summarized the salient aspects characterizing the four most popular toxic models of PD. Although all four neurotoxins reviewed here are thought to kill dopaminergic neurons, they all produce specific clinical or neuropathological abnormalities that make them different from each other. As we have stressed herein, each model has advantages and shortcomings, and none should be regarded as suitable to represent all aspects or to address all questions that pertain to PD. Thus, the take home message is that none of the presented models is perfect, and the selection of one over the other must be governed solely by the question and the type of investigations to be undertaken. In other words, we must always ask ourselves before embarking on a study using a model of PD: which model may be best suited to address the question to be investigated?

Acknowledgments: The authors thank Matthew Lucas for his assistance in preparing this manuscript and in the drawing of the chemical structures. The authors are supported by Na- tional Institutes of Health/National Institute of Neurological Disorders and Stroke Grants RO1 NS38586 and NS42269, P50 NS38370, and P01 NS11766-27A2, the U.S. Department of Defense Grant (DAMD 17-99-1-9474 and DAMD 17-03-1), the Lowenstein Foundation, the Lillian Goldman Charitable Trust, and the Parkinson's Disease Foundation.

\section{REFERENCES}

1. Fahn S, Przedborski S. Parkinsonism. In: Merritt's neurology (Rowland LP, ed), Ed 10, pp 679-693. New York: Lippincott Williams \& Wilkins, 2000.

2. Dauer W, Przedborski S. Parkinson's disease: mechanisms and models. Neuron 39:889-909, 2003.

3. Przedborski S, Goldman JE. Pathogenic role of glial cells in Parkinson's disease. In: Non-neuronal cells of the nervous system: function and dysfunction (Hertz L, ed), pp 967-982. New York: Elsevier, 2004.

4. Przedborski S, Tieu K. Toxic animal models. In: Neurodegenerative diseases: neurobiology, pathogenesis and therapeutics (Beal MF, Lang AE, Ludolph A, eds), pp 196-221. New York: Cambridge, 2005.

5. Przedborski S, Tieu K, Perier C, Vila M. MPTP as a mitochondrial neurotoxic model of Parkinson's disease. J Bioenerg Biomembr 36:375-379, 2004.

6. Przedborski S, Ischiropoulos H. Reactive oxygen and nitrogen species: weapons of neuronal destruction in models of Parkinson's disease. Antioxid Redox Signaling 7:685-693, 2005.

7. Jonsson G. Chemical lesioning techniques: monoamine neurotoxins. In: Handbook of chemical neuroanatomy. Methods in chemical neuroanatomy (Björklund A, Hökfelt T, eds), Ed 1, Vol 1, pp 463-507. Amsterdam: Elsevier Science Publishers B.V., 1983.

8. Roeling TA, Docter GJ, Voorn P, Melchers BP, Wolters EC, Groenewegen HJ. Effects of unilateral 6-hydroxydopamine lesions on neuropeptide immunoreactivity in the basal ganglia of the common marmoset, Callithrix jacchus, a quantitative immunohistochemical analysis. J Chem Neuroanat 9:155-164, 1995.

9. Annett LE, Torres EM, Clarke DJ, Ishida Y, Barker RA, Ridley RM, et al. Survival of nigral grafts within the striatum of marmosets with 6-OHDA lesions depends critically on donor embryo age. Cell Transplant 6:557-569, 1997.

10. Crofts HS, Dalley JW, Collins P, Van Denderen JC, Everitt BJ, Robbins TW, et al. Differential effects of 6-OHDA lesions of the frontal cortex and caudate nucleus on the ability to acquire an attentional set. Cereb Cortex 11:1015-1026, 2001.

11. Ma KH, Huang WS, Chen CH, Lin SZ, Wey SP, Ting G, et al. Dual SPECT of dopamine system using [99mTc]TRODAT-1 and [123I]IBZM in normal and 6-OHDA-lesioned formosan rock monkeys. Nucl Med Biol 29:561-567, 2002.

12. Soares-da-Silva P, Azevedo I. Differential effects of 6-hydroxydopamine on the two types of nerve vesicles and dopamine and noradrenaline content in mesenteric arterial vessels. J Auton Pharmacol 8:1-10, 1988.

13. Valette H, Deleuze P, Syrota A, Delforge J, Crouzel C, Fuseau C, et al. Canine myocardial beta-adrenergic, muscarinic receptor densities after denervation: a PET study. J Nucl Med 36:140-146, 1995.

14. Ruffy R, Leonard M. Chemical cardiac sympathetic denervation hampers defibrillation in the dog. J Cardiovasc Electrophysiol 8:62-67, 1997.

15. Jonsson G. Chemical neurotoxins as denervation tools in neurobiology. Annu Rev Neurosci 3:169-187, 1980.

16. Cohen G. Oxy-radical toxicity in catecholamine neurons. Neurotoxicology 5:77-82, 1984.

17. Saner A, Thoenen H. Model experiments on the molecular mechanism of action of 6- hydroxydopamine. Mol Pharmacol 7:147154, 1971.

18. Heikkila R, Cohen G. Inhibition of biogenic amine uptake by hydrogen peroxide: a mechanism for toxic effects of 6-hydroxydopamine. Science 172:1257-1258, 1971.

19. Mandel RJ, Randall PK. Quantification of lesion-induced dopaminergic supersensitivity using the rotational model in mouse. Brain Res 330:358-363, 1985. 
20. He Y, Appel S, Le W. Minocycline inhibits microglial activation and protects nigral cells after 6-hydroxydopamine injection into mouse striatum. Brain Res 909:187-193, 2001.

21. Lundblad M, Picconi B, Lindgren H, Cenci MA. A model of L-DOPA-induced dyskinesia in 6-hydroxydopamine lesioned mice: relation to motor and cellular parameters of nigrostriatal function. Neurobiol Dis 16:110-123, 2004.

22. Baker SA, Baker KA, Hagg T. Dopaminergic nigrostriatal projections regulate neural precursor proliferation in the adult mouse subventricular zone. Eur J Neurosci 20:575-579, 2004.

23. Ungerstedt U. Adipsia and aphagia after 6-hydroxydopamine induced degeneration of the nigro-striatal dopamine system. Acta Physiol Scand Suppl 367:95-122, 1971.

24. Bourn WM, Chin L, Picchioni AL. Enhancement of audiogenic seizure by 6-hydroxydopamine. J Pharm Pharmacol 24:913-914, 1972.

25. Ungerstedt U. 6-Hydroxydopamine induced degeneration of central monoamine neurons. Eur J Pharmacol 5:107-110, 1968.

26. Ungerstedt $U$. Stereotaxic mapping of the monoamine pathways in the rat brain. Acta Physiol Scand Suppl 367:1-48, 1971.

27. Javoy F, Sotelo C, Herbert A, Agid Y. Specificity of dopaminergic neuronal degeneration induced by intracerebral injection of 6-hydroxydopamine in the nigrostriatal dopamine system. Brain Res 102:210-215, 1976.

28. Jeon BS, Jackson-Lewis V, Burke RE. 6-Hydroxydopamine lesion of the rat substantia nigra: time course and morphology of cell death. Neurodegeneration 4:131-137, 1995.

29. Faull RL, Laverty R. Changes in dopamine levels in the corpus striatum following lesions in the substantia nigra. Exp Neurol 23:332-340, 1969.

30. Sarre S, Yuan H, Jonkers N, Van HA, Ebinger G, Michotte Y. In vivo characterization of somatodendritic dopamine release in the substantia nigra of 6-hydroxydopamine-lesioned rats. J Neurochem 90:29-39, 2004.

31. Przedborski S, Levivier M, Jiang H, Ferreira M, Jackson-Lewis $\mathrm{V}$, Donaldson D, et al. Dose-dependent lesions of the dopaminergic nigrostriatal pathway induced by intrastriatal injection of 6-hydroxydopamine. Neuroscience 67:631-647, 1995.

32. Sauer H, Oertel WH. Progressive degeneration of nigrostriatal dopamine neurons following intrastriatal terminal lesions with 6-hydroxydopamine: a combined retrograde tracing and immunocytochemical study in the rat. Neuroscience 59:401-415, 1994.

33. Marti MJ, James CJ, Oo TF, Kelly WJ, Burke RE. Early developmental destruction of terminals in the striatal target induces apoptosis in dopamine neurons of the substantia nigra. J Neurosci 17:2030-2039, 1997.

34. Stromberg I, Bjorklund H, Dahl D, Jonsson G, Sundstrom E, Olson L. Astrocyte responses to dopaminergic denervations by 6-hydroxydopamine and 1-methyl-4-phenyl-1,2,3,6-tetrahydropyridine as evidenced by glial fibrillary acidic protein immunohistochemistry. Brain Res Bull 17:225-236, 1986.

35. Saura J, Pares M, Bove J, Pezzi S, Alberch J, Marin C, et al. Intranigral infusion of interleukin- $1 \beta$ activates astrocytes and protects from subsequent 6-hydroxydopamine neurotoxicity. $\mathrm{J} \mathrm{Neu-}$ rochem 85:651-661, 2003.

36. Rodriguez DM, Abdala P, Barroso-Chinea P, Obeso J, GonzalezHernandez T. Motor behavioural changes after intracerebroventricular injection of 6-hydroxydopamine in the rat: an animal model of Parkinson's disease. Behav Brain Res 122:79-92, 2001.

37. Cenci MA, Whishaw IQ, Schallert T. Animal models of neurological deficits: how relevant is the rat? Nat Rev Neurosci 3:574$579,2002$.

38. Ungerstedt U, Arbuthnott G. Quantitative recording of rotational behaviour in rats after 6-hydroxydopamine lesions of the nigrostriatal dopamine system. Brain Res 24:485-493, 1970.

39. Hefti F, Melamed E, Wurtman RJ. Partial lesions of the dopaminergic nigrostriatal system in rat brain: biochemical characterization. Brain Res 195:123-137, 1980.

40. Jiang H, Jackson-Lewis V, Muthane U, Dollison A, Ferreira M, Espinosa A, et al. Adenosine receptor antagonists potentiate dopamine receptor agonist-induced rotational behavior in 6-hydroxydopamine- lesioned rats. Brain Res 613:347-351, 1993.

41. Kirik D, Georgievska B, Burger C, Winkler C, Muzyczka N,
Mandel RJ, et al. Reversal of motor impairments in parkinsonian rats by continuous intrastriatal delivery of L-dopa using rAAVmediated gene transfer. Proc Natl Acad Sci USA 99:4708-4713, 2002.

42. Bjorklund LM, Sanchez-Pernaute R, Chung S, Andersson T, Chen IY, McNaught KS, et al. Embryonic stem cells develop into functional dopaminergic neurons after transplantation in a Parkinson rat model. Proc Natl Acad Sci USA 99:2344-2349, 2002.

43. Papa SM, Engber TM, Kask AM, Chase TN. Motor fluctuations in levodopa treated parkinsonian rats: relation to lesion extent and treatment duration. Brain Res 662:69-74, 1994.

44. Bove J, Marin C, Bonastre M, Tolosa E. Adenosine A2A antagonism reverses levodopa-induced motor alterations in hemiparkinsonian rats. Synapse 46:251-257, 2002.

45. Olsson M, Nikkhah G, Bentlage C, Bjorklund A. Forelimb akinesia in the rat Parkinson model: differential effects of dopamine agonists and nigral transplants as assessed by a new stepping test. J Neurosci 15:3863-3875, 1995.

46. Hoglinger GU, Rizk P, Muriel MP, Duyckaerts C, Oertel WH, Caille I, et al. Dopamine depletion impairs precursor cell proliferation in Parkinson disease. Nat Neurosci 7:726-735, 2004.

47. Frielingsdorf H, Schwarz K, Brundin P, Mohapel P. No evidence for new dopaminergic neurons in the adult mammalian substantia nigra. Proc Natl Acad Sci USA 101:10177-10182, 2004.

48. Aebischer P, Tresco PA, Sagen J, Winn SR. Transplantation of microencapsulated bovine chromaffin cells reduces lesion-induced rotational asymmetry in rats. Brain Res 560:43-49, 1991.

49. Bal A, Savasta M, Chritin M, Mennicken F, Abrous DN, Le Moal $\mathrm{M}$, et al. Transplantation of fetal nigral cells reverses the increase of preproenkephalin mRNA levels in the rat striatum caused by 6-OHDA lesion of the dopaminergic nigrostriatal pathway: a quantitative in situ hybridization study. Mol Brain Res 18:221$227,1993$.

50. Venero JL, Beck KD, Hefti F. 6-Hydroxydopamine lesions reduce BDNF mRNA levels in adult rat brain substantia nigra. Neuroreport 5:429-432, 1994

51. St-Pierre JA, Bédard PJ. Intranigral but not intrastriatal microinjection of the NMDA antagonist MK-801 induces contralateral circling in the 6-OHDA rat model. Brain Res 660:255-260, 1994

52. Kearns CM, Cass WA, Smoot K, Kryscio R, Gash DM. GDNF protection against 6-OHDA: time dependence and requirement for protein synthesis. J Neurosci 17:7111-7118, 1997.

53. Nakao N, Nakai E, Nakai K, Itakura T. Ablation of the subthalamic nucleus supports the survival of nigral dopaminergic neurons after nigrostriatal lesions induced by the mitochondrial toxin 3-nitropropionic acid. Ann Neurol 45:640-651, 1999.

54. Chen L, Liu Z, Tian Z, Wang Y, Li S. Prevention of neurotoxin damage of 6-OHDA to dopaminergic nigral neuron by subthalamic nucleus lesions. Stereotact Funct Neurosurg 75:66-75, 2000.

55. Maesawa S, Kaneoke Y, Kajita Y, Usui N, Misawa N, Nakayama A, et al. Long-term stimulation of the subthalamic nucleus in hemiparkinsonian rats: neuroprotection of dopaminergic neurons. J Neurosurg 100:679-687, 2004.

56. Trugman JM, Wooten GF. Selective D1 and D2 dopamine agonists differentially alter basal ganglia glucose utilization in rats with unilateral 6-hydroxydopamine substantia nigra lesions. J Neurosci 7:2927-2935, 1987.

57. Gerfen CR, Baimbridge KG, Miller JJ. The neostriatal mosaic: Comparmental distribution of calcium-binding protein and parvalbumin in the basal ganglia of the rat and monkey. Proc Natl Acad Sci USA 82:8780-8784, 1985.

58. Gerfen CR, Baimbridge KG, Thibault J The neostriatal mosaic: III. Biochemical and developmental dissociation of patch-matrix nigrostriatal system. J Neurosci 7:3935-3944, 1987.

59. Gerfen CR, Herkenham M, Thibault J. The neostriatal mosaic: II Patch- and matrix-directed mesostriatal dopaminergic and nondopaminergic systems. J Neurosci 7:3915-3934, 1987.

60. Gerfen CR, Engber TM, Mahan LC, Susel Z, Chase TN, Monsma FJ, et al. D1 and D2 dopamine receptor-regulated gene expression of striatonigral and striatopallidal neurons. Science 250:14291432, 1990.

61. Blum D, Torch S, Lambeng N, Nissou M, Benabid AL, Sadoul R, 
et al. Molecular pathways involved in the neurotoxicity of 6-OHDA, dopamine and MPTP: contribution to the apoptotic theory in Parkinson's disease. Prog Neurobiol 65:135-172, 2001.

62. Langston JW, Ballard P, Irwin I. Chronic parkinsonism in humans due to a product of meperidine-analog synthesis. Science 219:979-980, 1983.

63. Kopin IJ. MPTP: an industrial chemical and contaminant of illicit narcotics stimulates a new era in research on Parkinson's disease. Environ Health Perspect 75:45-51, 1987.

64. Kitamura Y, Kakimura J, Taniguchi T. Protective effect of talipexole on MPTP-treated planarian, a unique parkinsonian worm model. Jpn J Pharmacol 78:23-29, 1998.

65. Przedborski S, Jackson-Lewis V, Naini A, Jakowec M, Petzinger $\mathrm{G}$, Miller R, et al. The parkinsonian toxin 1-methyl-4-phenyl1,2,3,6-tetrahydropyridine (MPTP): a technical review of its utility and safety. J Neurochem 76:1265-1274, 2001.

66. Przedborski S, Vila M. MPTP: a review of its mechanisms of neurotoxicity. Clin Neurosci Res 1:407-418, 2001.

67. Tetrud JW, Langston JW, Redmond DE Jr, Roth RH, Sladek JR, Angel RW. MPTP-induced tremor in human and non-human primates. Neurology 36(Suppl 1):308, 1986.

68. Stern Y. MPTP-induced parkinsonism. Prog Neurobiol 34:107114, 1990.

69. Stern Y, Tetrud JW, Martin WR, Kutner SJ, Langston JW. Cognitive change following MPTP exposure. Neurology 40:261-264, 1990.

70. Decamp E, Schneider JS. Attention and executive function deficits in chronic low-dose MPTP-treated non-human primates. Eur J Neurosci 20:1371-1378, 2004.

71. Kostic V, Przedborski S, Flaster E, Sternic N. Early development of levodopa-induced dyskinesias and response fluctuations in young-onset Parkinson's disease. Neurology 41:202-205, 1991.

72. Langston JW, Ballard P. Parkinsonism induced by 1-methyl-4phenyl-1,2,3,6-tetrahydropyridine (MPTP): implications for treatment and the pathogenesis of Parkinson's disease. Can J Neurol Sci 11:160-165, 1984.

73. Blanchet PJ, Calon F, Morissette M, Tahar AH, Belanger N, Samadi P, et al. Relevance of the MPTP primate model in the study of dyskinesia priming mechanisms. Parkinsonism Relat Disord 10:297-304, 2004.

74. Bézard E, Ferry S, Mach U, Stark H, Leriche L, Boraud T, et al. Attenuation of levodopa-induced dyskinesia by normalizing dopamine D3 receptor function. Nat Med 9:762-767, 2003.

75. Davis GC, Williams AC, Markey SP, Ebert MH, Caine ED, Reichert CM, et al. Chronic parkinsonism secondary to intravenous injection of meperidine analogs. Psychiatry Res 1:249-254, 1979.

76. Forno LS, DeLanney LE, Irwin I, Langston JW. Similarities and differences between MPTP-induced parkinsonism and Parkinson's disease: Neuropathologic considerations. Adv Neurol 60: 600-608, 1993.

77. Agid Y, Javoy-Agid F, Ruberg M. Biochemistry of neurotransmitters in Parkinson's disease. In: Movement disorders 2 (Marsden CD, Fahn S, eds), pp 166-230. London: Butterworths, 1987.

78. Seniuk NA, Tatton WG, Greenwood CE. Dose-dependent destruction of the coeruleus-cortical and nigral- striatal projections by MPTP. Brain Res 527:7-20, 1990.

79. Muthane U, Ramsay KA, Jiang H, Jackson-Lewis V, Donaldson $\mathrm{D}$, Fernando $\mathrm{S}$, et al. Differences in nigral neuron number and sensitivity to 1-methyl- 4-phenyl-1,2,3,6-tetrahydropyridine in C57/bl and CD-1mice. Exp Neurol 126:195-204, 1994.

80. Moratalla R, Quinn B, DeLanney LE, Irwin I, Langston JW, Graybiel AM. Differential vulnerability of primate caudate-putamen and striosome-matrix dopamine systems to the neurotoxic effects of 1- methyl-4-phenyl-1,2,3,6-tetrahydropyridine. Proc Natl Acad Sci USA 89:3859-3863, 1992.

81. Snow BJ, Vingerhoets FJ, Langston JW, Tetrud JW, Sossi V, Calne DB. Pattern of dopaminergic loss in the striatum of humans with MPTP induced parkinsonism. J Neurol Neurosurg Psychiat 68:313-316, 2000.

82. Forno LS, Langston JW, DeLanney LE, Irwin I, Ricaurte GA. Locus ceruleus lesions and eosinophilic inclusions in MPTPtreated monkeys. Ann Neurol 20:449-455, 1986.
83. Burns RS, Pakkenberg H, Kopin IJ. Lack of progression of MPTP-induced parkinsonism during long-term treatment with L-DOPA. Ann Neurol 18:117, 1985.

84. Vingerhoets FJ, Snow BJ, Tetrud JW, Langston JW, Schulzer M, Calne DB. Positron emission tomographic evidence for progression of human MPTP- induced dopaminergic lesions. Ann Neurol 36:765-770, 1994.

85. Langston JW, Forno LS, Tetrud J, Reeves AG, Kaplan JA, Karluk D. Evidence of active nerve cell degeneration in the substantia nigra of humans years after 1-methyl-4-phenyl-1,2,3,6-tetrahydropyridine exposure. Ann Neurol 46:598-605, 1999.

86. McGeer PL, Schwab C, Parent A, Doudet D. Presence of reactive microglia in monkey substantia nigra years after 1-methyl-4phenyl-1,2,3,6-tetrahydropyridine administration. Ann Neurol 54: 599-604, 2003.

87. Bergman H, Wichmann T, DeLong MR. Reversal of experimental parkinsonism by lesions of the subthalamic nucleus. Science 249:1436-1438, 1990.

88. Limousin P, Krack P, Pollak P, Benazzouz A, Ardouin C, Hoffmann $\mathrm{D}$, et al. Electrical stimulation of the subthalamic nucleus in advanced Parkinson's disease. N Engl J Med 339:1105-1111, 1998.

89. Gash DM, Zhang ZM, Ovadia A, Cass WA, Yi A, Simmerman L, et al. Functional recovery in parkinsonian monkeys treated with GDNF. Nature 380:252-255, 1996.

90. Kordower JH, Emborg ME, Bloch J, Ma SY, Chu Y, Leventhal L, et al. Neurodegeneration prevented by lentiviral vector delivery of GDNF in primate models of Parkinson's disease. Science 290:767-773, 2000.

91. Betarbet R, Sherer TB, MacKenzie G, Garcia-Osuna M, Panov AV, Greenamyre JT. Chronic systemic pesticide exposure reproduces features of Parkinson's disease. Nat Neurosci 3:1301-1306, 2000.

92. Hisata J. Final supplemental environmental impact statement. Lake and stream rehabilitation: rotenone use and health risks. Washington State Department of Fish and Wildlife, 2002.

93. Butterfield PG, Valanis BG, Spencer PS, Lindeman CA, Nutt JG. Environmental antecedents of young-onset Parkinson's disease. Neurology 43:1150-1158, 1993.

94. Gorell JM, Johnson CC, Rybicki BA, Peterson EL, Richardson RJ. The risk of Parkinson's disease with exposure to pesticides, farming, well water, and rural living. Neurology 50:1346-1350, 1998.

95. Marking L. Oral toxicity of rotenone to mammals. Investig Fish Control, Issue No. 94, 1988.

96. De Wilde AR, Heyndrickx A, Carton D. A case of fatal rotenone poisoning in a child. J Forensic Sci 31:1492-1498, 1986.

97. Talpade DJ, Greene JG, Higgins DS Jr, Greenamyre JT. In vivo labeling of mitochondrial complex I (NADH:ubiquinone oxidoreductase) in rat brain using [(3)H]dihydrorotenone. J Neurochem 75:2611-2621, 2000.

98. Schuler F, Casida JE. Functional coupling of PSST and ND1 subunits in NADH:ubiquinone oxidoreductase established by photoaffinity labeling. Biochim Biophys Acta 1506:79-87, 2001.

99. Marshall LE, Himes RH. Rotenone inhibition of tubulin selfassembly. Biochim Biophys Acta 543:590-594, 1978.

100. Brinkley BR, Barham SS, Barranco SC, Fuller GM. Rotenone inhibition of spindle microtubule assembly in mammalian cells. Exp Cell Res 85:41-46, 1974.

101. Burke D, Gasdaska P, Hartwell L. Dominant effects of tubulin overexpression in Saccharomyces cerevisiae. Mol Cell Biol 9:1049-1059, 1989.

102. Weinstein B, Solomon F. Phenotypic consequences of tubulin overproduction in Saccharomyces cerevisiae: differences between $\alpha$-tubulin and $\beta$-tubulin. Mol Cell Biol 10:5295-5304, 1990.

103. Ren Y, Zhao J, Feng J. Parkin binds to $\alpha / \beta$ tubulin and increases their ubiquitination and degradation. $J$ Neurosci 23:3316-3324, 2003.

104. Marey-Semper I, Gelman M, Lévi-Strauss M. A selective toxicity toward cultured mesencephalic dopaminergic neurons is induced by the synergistic effects of energetic metabolism impairment and NMDA receptor activation. $J$ Neurosci 15:5912-5918, 1995. 
105. Gao HM, Hong JS, Zhang W, Liu B. Distinct role for microglia in rotenone-induced degeneration of dopaminergic neurons. J Neurosci 22:782-790, 2002.

106. Heikkila RE, Nicklas WJ, Vyas I, Duvoisin RC. Dopaminergic toxicity of rotenone and the 1-methyl-4- phenylpyridinium ion after their stereotaxic administration to rats: implication for the mechanism of 1-methyl-4-phenyl-1,2,3,6- tetrahydropyridine toxicity. Neurosci Lett 62:389-394, 1985.

107. Ferrante RJ, Schulz JB, Kowall NW, Beal MF. Systemic administration of rotenone produces selective damage in the striatum and globus pallidus, but not in the substantia nigra. Brain Res 753:157-162, 1997.

108. Thiffault C, Langston JW, Di Monte DA. Increased striatal dopamine turnover following acute administration of rotenone to mice. Brain Res 885:283-288, 2000.

109. Sherer TB, Kim JH, Betarbet R, Greenamyre JT. Subcutaneous rotenone exposure causes highly selective dopaminergic degeneration and $\alpha$-synuclein aggregation. Exp Neurol 179:9-16, 2003.

110. Hoglinger GU, Feger J, Annick P, Michel PP, Karine P, Champy $\mathrm{P}$, et al. Chronic systemic complex I inhibition induces a hypokinetic multisystem degeneration in rats. J Neurochem 84:1-12, 2003.

111. Lapointe N, St-Hilaire M, Martinoli MG, Blanchet J, Gould P, Rouillard C, et al. Rotenone induces non-specific central nervous system and systemic toxicity. FASEB J 18:717-719, 2004.

112. Zhu C, Vourc'h P, Fernagut PO, Fleming SM, Lacan S, Dicarlo $\mathrm{CD}$, et al. Variable effects of chronic subcutaneous administration of rotenone on striatal histology. J Comp Neurol 478:418-426, 2004.

113. Alam M, Schmidt WJ. Rotenone destroys dopaminergic neurons and induces parkinsonian symptoms in rats. Behav Brain Res 136:317-324, 2002.

114. Alam M, Mayerhofer A, Schmidt WJ. The neurobehavioral changes induced by bilateral rotenone lesion in medial forebrain bundle of rats are reversed by L-DOPA. Behav Brain Res 151: 117-124, 2004.

115. Fleming SM, Zhu C, Fernagut PO, Mehta A, Dicarlo CD, Seaman RL, et al. Behavioral and immunohistochemical effects of chronic intravenous and subcutaneous infusions of varying doses of rotenone. Exp Neurol 187:418-429, 2004.

116. Day BJ, Patel M, Calavetta L, Chang LY, Stamler JS. A mechanism of paraquat toxicity involving nitric oxide synthase. Proc Natl Acad Sci USA 96:12760-12765, 1999.

117. Smith JG. Paraquat poisoning by skin absorption: a review. Hum Toxicol 7:15-19, 1988.

118. Grant H, Lantos PL, Parkinson C. Cerebral damage in paraquat poisoning. Histopathology 4:185-195, 1980.

119. Hughes JT. Brain damage due to paraquat poisoning: a fatal case with neuropathological examination of the brain. Neurotoxicology $9: 243-248,1988$.
120. Shimizu K, Ohtaki K, Matsubara K, Aoyama K, Uezono T, Saito $\mathrm{O}$, et al. Carrier-mediated processes in blood-brain barrier penetration and neural uptake of paraquat. Brain Res 906:135-142, 2001.

121. Liou HH, Tsai MC, Chen CJ, Jeng JS, Chang YC, Chen SY, et al. Environmental risk factors and Parkinson's disease: a case-control study in Taiwan. Neurology 48:1583-1588, 1997.

122. Brooks AI, Chadwick CA, Gelbard HA, Cory-Slechta DA, Federoff HJ. Paraquat elicited neurobehavioral syndrome caused by dopaminergic neuron loss. Brain Res 823:1-10, 1999.

123. McCormack AL, Di Monte DA. Effects of L-dopa and other amino acids against paraquat-induced nigrostriatal degeneration. J Neurochem 85:82-86, 2003.

124. Thiruchelvam M, Brockel BJ, Richfield EK, Baggs RB, CorySlechta DA. Potentiated and preferential effects of combined paraquat and maneb on nigrostriatal dopamine systems: environmental risk factors for Parkinson's disease? Brain Res 873:225234, 2000.

125. Thiruchelvam M, Richfield EK, Baggs RB, Tank AW, CorySlechta DA. The nigrostriatal dopaminergic system as a preferential target of repeated exposures to combined paraquat and maneb: implications for Parkinson's disease. J Neurosci 20:9207-9214, 2000.

126. McCormack AL, Thiruchelvam M, Manning-Bog AB, Thiffault C, Langston JW, Cory-Slechta DA, et al. Environmental risk factors and Parkinson's disease: selective degeneration of nigral dopaminergic neurons caused by the herbicide paraquat. Neurobiol Dis 10:119-127, 2002.

127. Manning-Bog AB, McCormack AL, Li J, Uversky VN, Fink AL, Di Monte DA. The herbicide paraquat causes up-regulation and aggregation of alpha-synuclein in mice: paraquat and $\alpha$-synuclein. J Biol Chem 277:1641-1644, 2002.

128. Manning-Bog AB, McCormack AL, Purisai MG, Bolin LM, Di Monte DA. $\alpha$-Synuclein overexpression protects against paraquat-induced neurodegeneration. J Neurosci 23:3095-3099, 2003.

129. Singleton AB, Farrer M, Johnson J, Singleton A, Hague S, Kachergus J, et al. $\alpha$-Synuclein locus triplication causes Parkinson's disease. Science 302:841, 2003.

130. Peng J, Mao XO, Stevenson FF, Hsu M, Andersen JK. The herbicide paraquat induces dopaminergic nigral apoptosis through sustained activation of the JNK pathway. J Biol Chem 279:32626-32632, 2004.

131. Thiruchelvam M, Richfield EK, Goodman BM, Baggs RB, CorySlechta DA. Developmental exposure to the pesticides paraquat and maneb and the Parkinson's disease phenotype. Neurotoxicology 23:621-633, 2002.

132. Barlow BK, Richfield EK, Cory-Slechta DA, Thiruchelvam M. A fetal risk factor for Parkinson's disease. Dev Neurosci 26:11-23, 2004. 